\title{
Differential expression of major histocompatibility complex class $I$ in subtypes of breast cancer is associated with estrogen receptor and interferon signaling
}

\author{
Hee Jin Lee ${ }^{1, *}$, In Hye Song ${ }^{1, *}$, In Ah Park ${ }^{1}$, Sun-Hee Heo ${ }^{1}$, Young-Ae Kim ${ }^{1}$, Jin-Hee \\ Ahn ${ }^{2}$ and Gyungyub Gong ${ }^{1}$ \\ ${ }^{1}$ Department of Pathology, University of Ulsan College of Medicine, Asan Medical Center, Seoul, Korea \\ 2 Department of Oncology, University of Ulsan College of Medicine, Asan Medical Center, Seoul, Korea \\ * These authors have contributed equally to this work \\ Correspondence to: Gyungyub Gong, email: gygong@amc.seoul.kr \\ Keywords: breast carcinoma; tumor-infiltrating lymphocytes; major histocompatibility complex I; human leukocyte antigen; Pa- \\ thology Section \\ Received: December 14, $2015 \quad$ Accepted: April 03, 2016 \\ Published: April 18, 2016
}

\section{ABSTRACT}

Tumor-infiltrating lymphocytes (TILs) in triple-negative breast cancer (TNBC) have a strong prognostic and predictive significance. However, the mechanism of TIL influx in TNBC is unclear. Expression of major histocompatibility complex class I (MHC I) on the tumor cell is essential for the effective killing of tumor by cytotoxic TILs. In our current study, human leukocyte antigen (HLA) expression was inversely correlated with estrogen receptor (ER) expression in normal and cancerous breast tissue and positively correlated with TILs in breast cancer. The ER score was inversely correlated with TILs in breast cancer. HLA-A and CD8B gene expression was negatively correlated with ESR1 and positively correlated with interferon-associated gene expression in The Cancer Genome Atlas (TCGA) data. Negative correlation between ESR1 and HLA and positive correlation between interferon-associated and HLA gene expression were also confirmed in Cancer Cell Line Encyclopedia (CCLE) data. Taken together, our data suggest that a lower expression of HLA in luminal-type tumors might be associated with low level of TILs in those tumors. Further investigation of the mechanism of higher HLA expression and TIL influx in TNBC may help to boost the host immune response.

\section{INTRODUCTION}

The importance of tumor-infiltrating lymphocytes (TILs) in breast cancer has been consistently documented [1-7]. TILs have a strong prognostic and predictive significance, particularly in triple-negative breast cancer (TNBC). Cytotoxic CD8 ${ }^{+}$TILs are only activated by $\mathrm{T}$ cell receptor-recognition of a specific peptide, which is mostly generated from endogenous proteins, presented by a major histocompatibility complex class I (MHC I) on the surface of tumor cells [8]. The recognition of these peptides by cytotoxic $\mathrm{CD} 8^{+}$TILs triggers a series of events that can result in tumor cell lysis. Better understanding of TILs and related features could facilitate the development of efficient immunotherapeutic approaches in breast cancer.

MHC I proteins are membrane proteins expressed on almost all nucleated cells and encoded by human leukocyte antigen $(H L A)-A,-B$, and $-C$ genes [9]. Expression of $H L A$ s varies from tissue to tissue and is largely stimulated by interferon (IFN) signaling $[10,11]$. Downregulation of $H L A \mathrm{~s}$ is frequently seen in tumors and is reported to be correlated with disease progression [10]. Aberrant HLA expression in tumor cells might be caused by alteration of $H L A$ gene transcription, translation of $H L A$ mRNA, or post-translational modification. Torigoe et al. [12] established a monoclonal anti-pan HLA class I antibody suitable for immunostaining of formalin-fixed tissue and found a high rate $(85 \%, 35$ out of 41 cases) of HLA downregulation in breast cancer compared with other malignancies (20\%-42\%). Since HLA expression on tumor cells is important for the function of TILs, downregulation of HLA might compromise the effective immune response 
in patients with breast cancer. Moreover, increased IFN signaling in cancer cells and their association with good response to anthracycline-based chemotherapy have been recently reported in breast cancer [13]. However, HLA expression, the level of IFN signaling activation, and their relationship in normal breast tissue and each subtype of breast cancer have not been extensively studied.

In our previous study, we reported that HLA-ABC and HLA-A expressions were positively correlated with TILs in HER2 $2^{+}$tumors that had been treated with adjuvant trastuzumab (Spearman correlation: rho $=0.246, P<$ 0.001 for HLA-ABC expression and TILs; rho $=0.249, P$ $<0.001$ for HLA-A expression and TILs) [14]. However, HLA expression was not associated with the HER 2 gene amplification or HER2 overexpression, which may suggest that HER2 itself is not the factor that influences the level of TILs. HER2 ${ }^{+}$breast cancer and TNBC are well known to be associated with increased cancer cell proliferation and genomic instability but interestingly, TIL levels were found to be higher in both HER2 ${ }^{+}$breast cancer and TNBC than in $\mathrm{ER}^{+} / \mathrm{HER} 2^{-}$tumors [1]. We therefore hypothesized that genomic instability would produce more mutations, some of which are presented on tumor cells by HLA proteins, and induce a potent anti-tumor immune response. Consequently, an increased immune reaction would produce high levels of interferon-gamma (IFN $\gamma$ ), which can induce transcription of the HLA gene [10]. However, the relationships between the mutation rate and degree of TIL or HLA expression have not been studied in each type of breast cancer.

In our current study, we evaluated TILs and expression of HLA-ABC in two cohorts of breast cancer and HLA-ABC expression in normal breast tissue. The relationship among expression of ESR1, HLAs, and IFN-associated molecules was analyzed from The Cancer Genome Atlas (TCGA) and Cancer Cell Line Encyclopedia (CCLE) data. We also investigated correlation between $H L A$ gene expression and mutation rate from TCGA data.

\section{RESULTS}

\section{TILs and expression of HLA class $I$ in breast cancer samples}

To explore the expression of HLA and its relationship with TIL in each subtype of breast cancer, we analyzed 688 consecutive breast cancer cohort (Table 1). The histologic grade and TIL levels were higher in TNBC and hormone receptor negative $\left(\mathrm{HR}^{-}\right) / \mathrm{HER}^{+}$ tumors. While $22 \%$ of $\mathrm{HR}^{+} / \mathrm{HER} 2^{-}$tumors showed strong HLA-ABC expression in tumor cells, more than half of TNBCs were strongly positive for HLA-ABC by immunohistochemistry (Figure 1A). Lymphocytes were strongly positive for HLA-ABC in all subtypes and stromal cells in adjacent stroma of TNBC and $\mathrm{HR}^{-} / \mathrm{HER} 2^{+}$ tumors showed stronger HLA-ABC expression than those

A
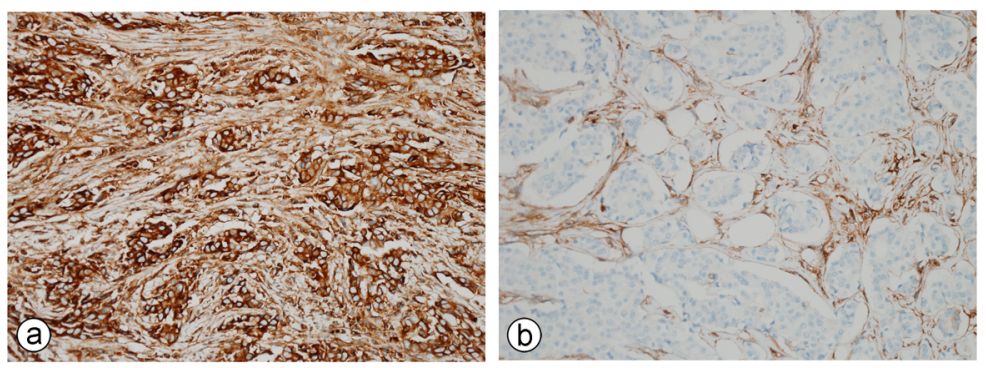

B
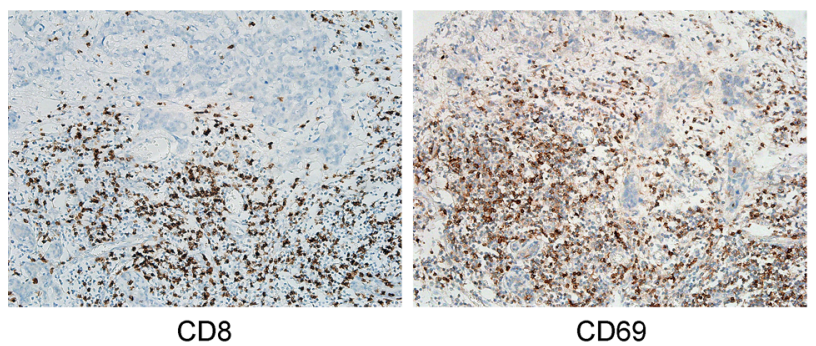

CD69

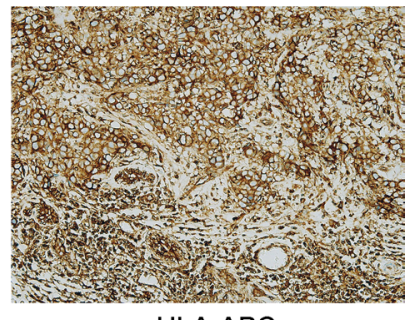

HLA-ABC

Figure 1: A. Representative figures of HLA-ABC expression in breast cancer. (a) Tumor and stromal cells strongly positive for HLAABC. (b) Tumor cells negative for HLA-ABC. B. CD8 and CD69 expressing cells and HLA-ABC expression in tumor cells of a case in validation TNBC cohort. 
Table 1: Comparison of pathologic variables according to breast cancer subtype in the first consecutively resected cohort

\begin{tabular}{|c|c|c|c|c|c|}
\hline Variables & $\mathrm{HR}^{+} / \mathrm{HER}^{-}$ & $\mathrm{HR}^{+} / \mathrm{HER}^{-}$ & HR-/HER2 $^{+}$ & TNBC & $P$ \\
\hline Histologic type & & & & & 0.016 \\
\hline Invasive carcinoma of no special type & $331(88.7)$ & $43(97.7)$ & $75(92.6)$ & $174(91.6)$ & \\
\hline Carcinoma with medullary features & $0(0.0)$ & $0(0.0)$ & $0(0.0)$ & $4(2.1)$ & \\
\hline Carcinoma with mucinous features & $3(0.8)$ & $0(0.0)$ & $0(0.0)$ & $0(0.0)$ & \\
\hline Invasive micropapillary carcinoma & $12(3.2)$ & $1(2.3)$ & $5(6.2)$ & $5(2.6)$ & \\
\hline Mucinous carcinoma & $10(2.7)$ & $0(0.0)$ & $1(1.2)$ & $0(0.0)$ & \\
\hline Metaplastic carcinoma & $1(0.3)$ & $0(0.0)$ & $0(0.0)$ & $4(2.1)$ & \\
\hline Invasive lobular carcinoma & $14(3.8)$ & $0(0.0)$ & $0(0.0)$ & $3(1.6)$ & \\
\hline Tubular carcinoma & $2(0.5)$ & $0(0.0)$ & $0(0.0)$ & $0(0.0)$ & \\
\hline Histologic grade & & & & & $<0.001$ \\
\hline 1 & $82(22.0)$ & $4(9.1)$ & $1(1.2)$ & $4(2.1)$ & \\
\hline 2 & $217(58.2)$ & $25(56.8)$ & $34(42.0)$ & $51(26.8)$ & \\
\hline 3 & $74(19.8)$ & $15(34.1)$ & $46(56.8)$ & $135(71.1)$ & \\
\hline pT & & & & & $<0.001$ \\
\hline 1 & $151(40.5)$ & $15(34.1)$ & $19(23.5)$ & $51(26.8)$ & \\
\hline 2 & $189(50.7)$ & $23(52.3)$ & $49(60.5)$ & $110(57.9)$ & \\
\hline 3 & $28(7.5)$ & $5(11.4)$ & $12(14.8)$ & $20(10.5)$ & \\
\hline 4 & $5(1.3)$ & $1(2.3)$ & $1(1.2)$ & $9(4.7)$ & \\
\hline Lymph node metastasis & & & & & 0.731 \\
\hline Negative & $176(48.1)$ & $15(34.1)$ & $34(42.0)$ & $94(50.8)$ & \\
\hline Positive & $190(51.9)$ & $29(65.9)$ & $47(58.0)$ & $91(49.2)$ & \\
\hline Lymphovascular invasion & & & & & 0.064 \\
\hline Negative & $248(66.5)$ & $27(64.3)$ & $48(59.3)$ & $145(76.3)$ & \\
\hline Positive & $125(33.5)$ & $15(35.7)$ & $33(40.7)$ & $45(23.7)$ & \\
\hline pTNM stage & & & & & 0.044 \\
\hline $\mathrm{I}$ & $100(26.8)$ & $7(15.9)$ & $14(17.3)$ & $38(20.0)$ & \\
\hline II & $173(46.4)$ & $22(50.0)$ & $35(43.2)$ & $96(50.5)$ & \\
\hline III & $99(26.5)$ & $15(34.1)$ & $32(39.5)$ & $54(28.4)$ & \\
\hline IV & $1(0.3)$ & $0(0.0)$ & $0(0.0)$ & $2(1.1)$ & \\
\hline Hormone therapy & & & & & $<0.001$ \\
\hline Negative & $74(19.8)$ & $5(11.4)$ & $36(44.4)$ & $114(60.0)$ & \\
\hline Positive & $299(80.2)$ & $39(88.6)$ & $45(55.6)$ & $76(40.0)$ & \\
\hline Radiotherapy & & & & & 0.254 \\
\hline Negative & $283(75.9)$ & $27(61.4)$ & $60(74.1)$ & $135(71.1)$ & \\
\hline Positive & $90(24.1)$ & $17(38.6)$ & $21(25.9)$ & $55(28.9)$ & \\
\hline Chemotherapy & & & & & $<0.001$ \\
\hline None & $171(45.8)$ & $10(22.7)$ & $20(24.7)$ & $38(20.0)$ & \\
\hline Unknown regimen & $8(2.1)$ & $0(0.0)$ & $0(0.0)$ & $6(3.2)$ & \\
\hline Anthracycline-based & $36(9.7)$ & $12(27.3)$ & $16(19.8)$ & $26(13.7)$ & \\
\hline Methotrexate-based & $158(42.4)$ & $22(50.0)$ & $45(55.6)$ & $120(63.2)$ & \\
\hline Tumor-infiltrating lymphocytes & & & & & $<0.001$ \\
\hline$\leq 10 \%$ & $283(75.8)$ & $27(61.4)$ & $31(38.3)$ & $62(32.6)$ & \\
\hline $20-30 \%$ & $57(15.3)$ & $12(27.3)$ & $25(30.9)$ & $50(26.3)$ & \\
\hline $40 \%-60 \%$ & $19(5.1)$ & $5(11.3)$ & $12(14.8)$ & $34(17.9)$ & \\
\hline$>60 \%$ & $14(3.8)$ & $0(0.0)$ & $13(16.0)$ & $44(23.2)$ & \\
\hline HLA-ABC expression in tumor cells & & & & & $<0.001$ \\
\hline
\end{tabular}




\begin{tabular}{|l|l|l|l|l|l|}
\hline Negative & $213(58.7)$ & $16(37.2)$ & $38(47.5)$ & $64(34.4)$ & \\
\hline Weakly positive & $70(19.3)$ & $15(34.9)$ & $17(21.3)$ & $26(14.0)$ & \\
\hline Strongly positive & $80(22.0)$ & $12(27.9)$ & $25(31.3)$ & $96(51.6)$ & \\
\hline HLA-ABC intensity in stromal cells & & & & & $<0.001$ \\
\hline 1 & $53(14.5)$ & $1(2.3)$ & $1(1.2)$ & $8(4.3)$ & \\
\hline 2 & $221(60.2)$ & $27(62.8)$ & $35(43.2)$ & $70(37.2)$ & \\
\hline 3 & $93(25.3)$ & $15(34.9)$ & $45(55.6)$ & $110(58.5)$ & \\
\hline
\end{tabular}

$\mathrm{HR}$, hormone receptor; TNBC, triple-negative breast cancer.

of $\mathrm{HR}^{+}$tumors. In all tumors, the ER Allred score was inversely correlated with the HLA-ABC immunoreactive score (rho $=-0.177, P<0.001$ ) and TIL percentage (rho $=-0.378, P<0.001)$. HLA-ABC expression was significantly correlated with TIL level (rho $=0.442, P<$ $0.001)$.

A
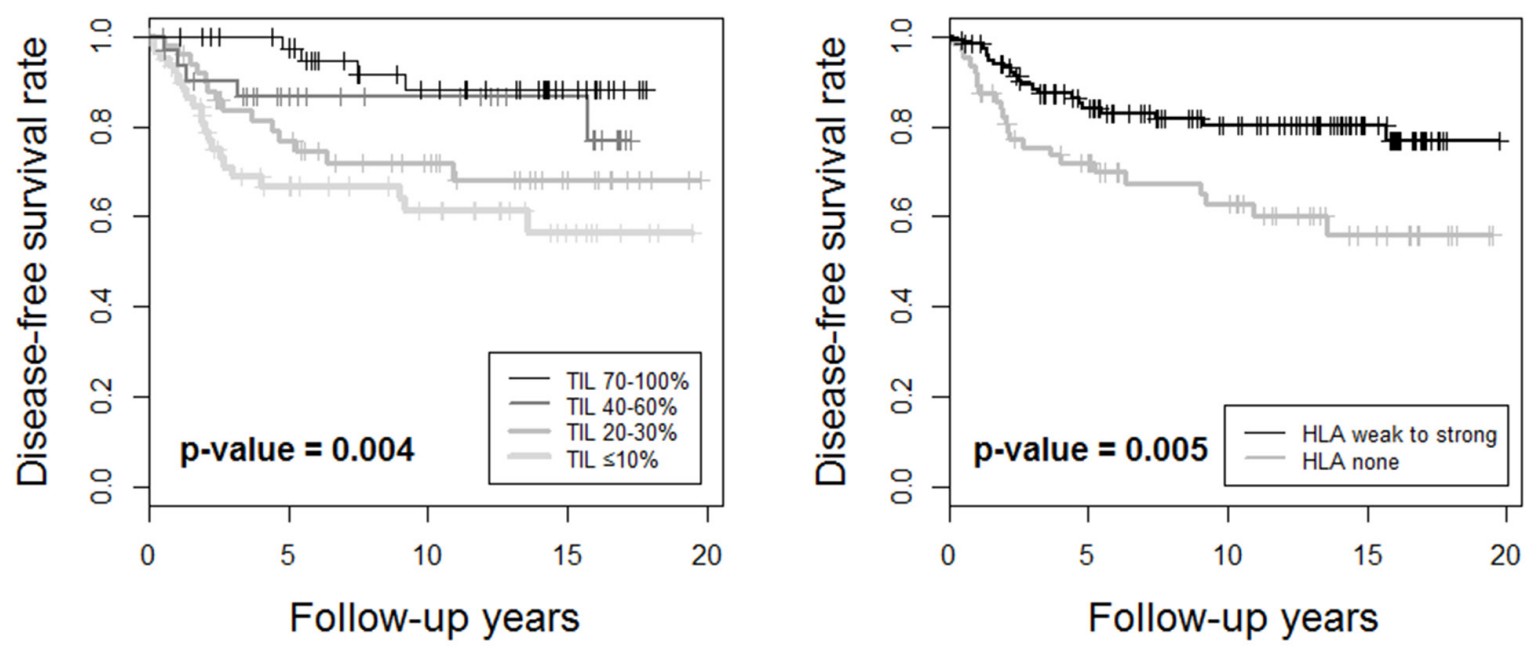

Follow-up years

B
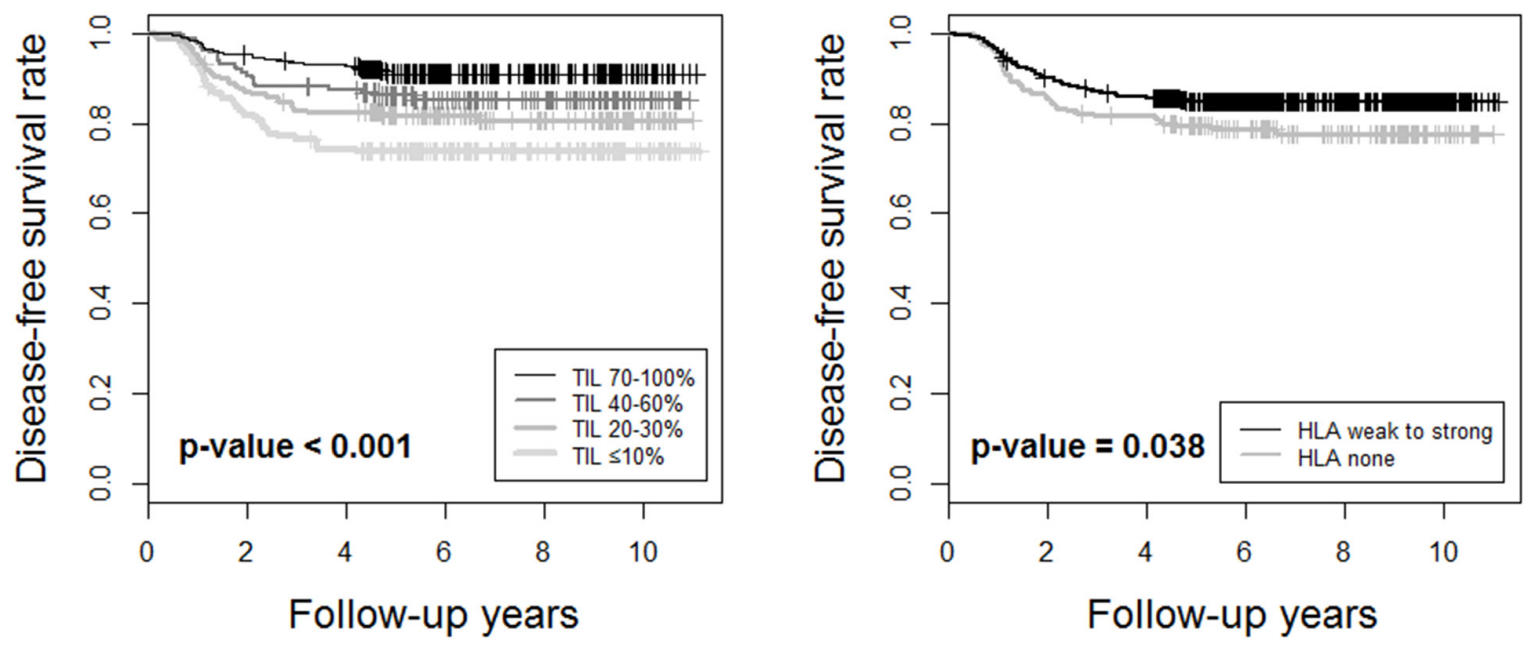

Figure 2: Kaplan-Meier survival curves for A. TNBCs in the consecutive breast cancer cohort and B. validation TNBC cohort, in terms of Tumor-infiltrating lymphocyte levels and HLA-ABC expression levels in tumor cells. 
Table 2: Comparison of pathologic factors in TNBCs within the consecutive breast cancer cohort according to HLA$\mathrm{ABC}$ expression in tumor cells

\begin{tabular}{|c|c|c|c|c|}
\hline \multirow[b]{2}{*}{ Variables } & \multicolumn{3}{|c|}{ HLA-ABC expression } & \multirow[b]{2}{*}{$\boldsymbol{P}$} \\
\hline & Negative & $\begin{array}{l}\text { Weakly } \\
\text { positive }\end{array}$ & $\begin{array}{l}\text { Strongly } \\
\text { positive }\end{array}$ & \\
\hline Histology & & & & 0.008 \\
\hline Invasive carcinoma of no special type & $62(96.9)$ & $20(77.0)$ & $89(92.7)$ & \\
\hline Carcinoma with medullary features & $0(0.0)$ & $1(3.8)$ & $3(3.1)$ & \\
\hline Invasive micropapillary carcinoma & $2(3.1)$ & $1(3.8)$ & $2(2.1)$ & \\
\hline Metaplastic carcinoma & $0(0.0)$ & $2(7.7)$ & $2(2.1)$ & \\
\hline Invasive lobular carcinoma & $0(0.0)$ & $2(7.7)$ & $0(0.0)$ & \\
\hline Histologic grade & & & & 0.001 \\
\hline 1 & $2(3.1)$ & $1(3.8)$ & $0(0.0)$ & \\
\hline 2 & $24(37.5)$ & $9(34.6)$ & $17(17.7)$ & \\
\hline 3 & $38(59.4)$ & $16(61.5)$ & $79(82.3)$ & \\
\hline $\mathrm{pT}$ & & & & 0.140 \\
\hline 1 & $16(25.0)$ & $7(26.9)$ & $27(28.1)$ & \\
\hline 2 & $33(51.6)$ & $17(65.4)$ & $58(60.4)$ & \\
\hline 3 & $10(15.6)$ & $2(7.7)$ & $7(7.3)$ & \\
\hline 4 & $5(7.8)$ & $0(0.0)$ & $4(4.2)$ & \\
\hline Lymphovascular invasion & & & & 0.010 \\
\hline Negative & $42(65.6)$ & $20(76.9)$ & $80(83.3)$ & \\
\hline Positive & $22(34.4)$ & $6(23.1)$ & $16(16.7)$ & \\
\hline Lymph node metastasis & & & & 0.124 \\
\hline Negative & $26(42.6)$ & $13(50.0)$ & $52(55.3)$ & \\
\hline Positive & $35(57.4)$ & $13(50.0)$ & $42(44.7)$ & \\
\hline Adjuvant systemic therapy & & & & 0.165 \\
\hline None & $16(25.0)$ & $5(19.2)$ & $16(16.7)$ & \\
\hline Unknown regimen & $1(1.6)$ & $0(0.0)$ & $5(5.2)$ & \\
\hline Anthracycline-based & $12(18.7)$ & $5(19.2)$ & $8(8.3)$ & \\
\hline Methotrexate-based & $35(54.7)$ & $16(61.6)$ & $67(69.8)$ & \\
\hline Radiation therapy & & & & 0.072 \\
\hline Negative & $42(65.6)$ & $16(61.5)$ & $75(78.1)$ & \\
\hline Positive & $22(34.4)$ & $10(38.5)$ & $21(21.9)$ & \\
\hline Hormone therapy & & & & 0.559 \\
\hline Negative & $37(57.8)$ & $16(61.5)$ & $60(62.5)$ & \\
\hline Positive & $27(42.2)$ & $10(38.5)$ & $36(37.5)$ & \\
\hline Basal type & & & & 0.014 \\
\hline Negative & $40(62.5)$ & $18(69.2)$ & $42(43.8)$ & \\
\hline Positive & $24(37.5)$ & $8(30.8)$ & $54(56.3)$ & \\
\hline Tumor-infiltrating lymphocytes & & & & $<0.001$ \\
\hline$\leq 10 \%$ & $32(50.0)$ & $14(53.8)$ & $16(16.7)$ & \\
\hline $20-30 \%$ & $21(32.8)$ & $5(19.2)$ & $21(21.9)$ & \\
\hline $40 \%-60 \%$ & $7(10.9)$ & $3(11.5)$ & $24(25.0)$ & \\
\hline$>60 \%$ & $4(6.3)$ & $4(15.4)$ & $35(36.5)$ & \\
\hline HLA-ABC intensity in stromal cells & & & & $<0.001$ \\
\hline 1 & $6(9.4)$ & $1(3.8)$ & $1(1.0)$ & \\
\hline 2 & $38(59.4)$ & $13(50.0)$ & $17(17.7)$ & \\
\hline 3 & $20(31.3)$ & $12(46.2)$ & $78(81.3)$ & \\
\hline
\end{tabular}


Table 3: Correlations among variables on lymphocytes and HLA-ABC expression in the validation TNBC cohort (correlation coefficient rho and $P$ value)

\begin{tabular}{|l|l|l|l|}
\hline & $\begin{array}{l}\text { Number of } \text { CD8 }^{+} \\
\text {cells }\end{array}$ & $\begin{array}{l}\text { Number of CD69 } \\
\text { cells }\end{array}$ & $\begin{array}{l}\text { HLA-ABC } \\
\text { expression }\end{array}$ \\
\hline $\begin{array}{l}\text { Tumor infiltrating lymphocyte on H\&E } \\
\text { staining }\end{array}$ & $0.627(<0.001)$ & $0.674(<0.001)$ & $0.420(<0.001)$ \\
\hline Number of $\mathrm{CD}^{+}$cells & & $0.869(<0.001)$ & $0.467(<0.001)$ \\
\hline Number of CD69 $9^{+}$cells & & & $0.571(<0.001)$ \\
\hline
\end{tabular}

Table 4: Survival analyses of clinicopathologic variables that affect clinical outcomes of TNBC cases in the consecutive breast cancer cohort

\begin{tabular}{|l|l|l|l|l|l|l|}
\hline Variables & \multicolumn{4}{l|}{ Univariate } & \multicolumn{2}{l|}{ Multivariate } \\
\hline & $\begin{array}{l}\text { Hazard } \\
\text { ratio }\end{array}$ & $\mathbf{9 5 \%}$ CI & $\begin{array}{l}\boldsymbol{P} \\
\text { value }\end{array}$ & $\begin{array}{l}\text { Hazard } \\
\text { ratio }\end{array}$ & $\mathbf{9 5 \% ~ C I ~}$ & $\begin{array}{l}\boldsymbol{P} \\
\text { value }\end{array}$ \\
\hline Age: $\geq 50$ years $v s .<50$ & 0.952 & $0.515-1.763$ & 0.876 & 1.198 & $0.615-2.336$ & 0.595 \\
\hline Histologic grade: 3 vs. $1 / 2$ & 0.713 & $0.585-0.868$ & 0.001 & 0.904 & $0.720-1.134$ & 0.381 \\
\hline pT: $3 / 4$ vs. $1 / 2$ & 3.316 & $1.732-6.345$ & $<0.001$ & 1.632 & $0.794-3.356$ & 0.183 \\
\hline $\begin{array}{l}\text { Lymph node metastasis: } \\
\text { positive } v s . \text { negative }\end{array}$ & 7.729 & $3.247-18.395$ & $<0.001$ & 5.877 & $2.396-14.413$ & $<0.001$ \\
\hline TILs (per 10\%) expression: & 0.975 & $0.960-0.989$ & 0.001 & 0.980 & $0.963-0.997$ & 0.023 \\
\hline $\begin{array}{l}\text { HLA-ABC } \\
\text { strongly/weakly positive vs. } \\
\text { negative }\end{array}$ & 0.661 & $0.492-0.889$ & 0.005 & 0.886 & $0.626-1.255$ & 0.496 \\
\hline
\end{tabular}

CI, confidence interval; TIL, tumor infiltrating lymphocyte.

Since TILs are abundant $(28.7 \pm 27.7 \%$ in TNBC; $15.9 \pm 22.2 \%$ in all tumors) and strong HLA-ABC expression is most frequent in TNBC, we analyzed the correlation between TILs and HLA-ABC expression and their prognostic significance in TNBCs included in our consecutive breast cancer series and validated the relationship in a separate cohort with a large number of TNBCs. In TNBCs within the first consecutive breast cancer cohort, a strong HLA-ABC expression was significantly correlated with a higher histologic grade, absence of lymphovascular invasion, basal type, higher TIL level, and stronger HLA-ABC expression in stromal cells (Table 2). In the validation TNBC cohort, a strong HLA-ABC expression in tumor cells was also significantly correlated with a higher histologic grade, basal type, higher TIL level, and stronger HLA-ABC expression in stromal cells (Supplementary Table S1). We also examined the numbers of $\mathrm{CD} 8^{+} \mathrm{T}$ cells and $\mathrm{CD} 69^{+}$activated immune cells in this validation TNBC cohort, and strong positive correlations were found between the numbers of $\mathrm{CD} 8^{+}$or $\mathrm{CD}^{+} 9^{+}$cells and the HLA-ABC expression in tumor cells as well as the TIL levels assessed on the H\&E stained slides. (Figure 1B and Table 3).

The prognostic significance of TILs and other clinicopathologic variables in TNBCs was analyzed. In TNBCs within the consecutive breast cancer cohort, higher histologic grade, lower $\mathrm{pT}$ stage, absence of lymph node metastasis, higher TIL level, and presence of HLA$\mathrm{ABC}$ expression were associated with better disease- free survival (Table 4 and Figure 2A). In multivariate analysis, only lymph node metastasis and TIL level were independent prognostic factors for disease-free survival. In the validation TNBC cohort, lower $\mathrm{pT}$ stage, absence of lymph node metastasis, higher TIL level, and presence of HLA-ABC expression were also associated with better outcome (Supplementary Table S2 and Figure 2B). Again, lymph node metastasis and TIL level were independent prognostic factors for disease-free survival in this validation group.

\section{HLA-ABC expression in non-neoplastic breast tissue}

Because HLA-ABC expression was lowest in $\mathrm{HR}^{+} /$ HER2- tumors in our consecutive breast cancer samples, we hypothesized that the expression level of HLA-ABC might be associated with HR status. We examined ER, cytokeratin 5 (CK5), and HLA-ABC expression in tissue from reduction mammoplasty and mammary hamartoma cases. The ER Allred scores varied in each case (a score of 5 in 4 cases, 6 in 9 cases, 7 in 10 cases, and 8 in 14 cases). Compared with the expression intensity of HLA-ABC in breast cancer, normal luminal cells generally weakly expressed HLA-ABC (Figure 3). The immunoreactive score of HLA-ABC expression was inversely correlated with the ER Allred score (rho $=-0.339, P=0.04$ ) in normal luminal cells between patients. CK5 expression 
Table 5: Comparison of immune-related gene expression and number of mutations according to the molecular subtype in the TCGA data

\begin{tabular}{|c|c|c|c|c|c|}
\hline Variables & $\begin{array}{l}\text { Luminal A } \\
(n=168)\end{array}$ & $\begin{array}{l}\text { Luminal B } \\
(n=96)\end{array}$ & \begin{tabular}{|l} 
HER2- \\
enriched \\
$(n=48)$
\end{tabular} & $\begin{array}{l}\text { Basal-like } \\
(n=84)\end{array}$ & $P$ \\
\hline ESR1 & $0.59 \pm 1.07$ & $0.75 \pm 0.99$ & $-3.14 \pm 2.22$ & $-5.24 \pm 1.76$ & $<0.001$ \\
\hline$E R B B 2$ & $0.21 \pm 0.78$ & $0.13 \pm 1.00$ & $1.88 \pm 1.39$ & $-0.65 \pm 0.89$ & $<0.001$ \\
\hline$C D 3 D$ & $-0.10 \pm 0.96$ & $0.01 \pm 1.13$ & $0.44 \pm 1.02$ & $0.45 \pm 1.25$ & $<0.001$ \\
\hline$C D 3 E$ & $-0.5 \pm 0.36$ & $0.04 \pm 0.46$ & $0.24 \pm 0.41$ & $0.24 \pm 0.48$ & $<0.001$ \\
\hline$C D 3 G$ & $-0.16 \pm 1.24$ & $-0.17 \pm 1.38$ & $0.42 \pm 1.32$ & $0.34 \pm 1.61$ & 0.009 \\
\hline$C D 8 B$ & $-0.04 \pm 0.68$ & $-0.11 \pm 0.89$ & $0.23 \pm 0.81$ & $0.60 \pm 1.00$ & $<0.001$ \\
\hline$H L A-A$ & $-0.13 \pm 0.78$ & $0.01 \pm 0.92$ & $0.17 \pm 0.81$ & $0.18 \pm 1.01$ & 0.012 \\
\hline$H L A-B$ & $-0.09 \pm 0.89$ & $0.03 \pm 1.01$ & $0.02 \pm 1.01$ & $0.13 \pm 1.20$ & 0.288 \\
\hline$H L A-C$ & $-0.11 \pm 0.69$ & $-0.02 \pm 0.78$ & $0.09 \pm 0.73$ & $0.11 \pm 0.86$ & 0.04 \\
\hline$M X 1$ & $-0.18 \pm 0.83$ & $0.03 \pm 1.05$ & $0.01 \pm 0.71$ & $0.07 \pm 1.04$ & 0.015 \\
\hline IFNAR1 & $-0.08 \pm 0.33$ & $0.06 \pm 0.48$ & $-0.31 \pm 0.51$ & $0.10 \pm 0.56$ & $<0.001$ \\
\hline IFNAR2 & $-0.13 \pm 0.43$ & $-0.07 \pm 0.58$ & $0.27 \pm 0.61$ & $0.79 \pm 0.59$ & $<0.001$ \\
\hline IFNGRI & $0.05 \pm 0.55$ & $-0.31 \pm 0.53$ & $0.20 \pm 0.75$ & $0.39 \pm 0.69$ & $<0.001$ \\
\hline IFNGR2 & $0.04 \pm 0.41$ & $-0.17 \pm 0.48$ & $0.14 \pm 0.44$ & $0.15 \pm 0.61$ & 0.001 \\
\hline $\begin{array}{l}\text { Total number of insertions and deletions } \\
\text { number of frameshift deletion } \\
\text { number of frameshift insertion } \\
\text { number of in-frame deletion } \\
\text { number of in-frame insertion }\end{array}$ & $\begin{array}{l}3.5 \pm 3.4 \\
2.0 \pm 2.1 \\
0.7 \pm 0.8 \\
0.7 \pm 1.5 \\
0.2 \pm 0.6\end{array}$ & $\begin{array}{l}4.4 \pm 3.4 \\
2.6 \pm 2.6 \\
0.7 \pm 0.8 \\
1.0 \pm 1.3 \\
0.1 \pm 0.4 \\
\end{array}$ & $\begin{array}{l}3.1 \pm 2.3 \\
1.8 \pm 1.8 \\
0.7 \pm 0.8 \\
0.5 \pm 0.7 \\
0.1 \pm 0.4\end{array}$ & $\begin{array}{l}6.3 \pm 5.2 \\
3.8 \pm 3.3 \\
0.7 \pm 1.3 \\
1.5 \pm 1.6 \\
0.3 \pm 0.5\end{array}$ & $<0.001$ \\
\hline $\begin{array}{l}\text { Total number of point mutations } \\
\text { number of missense mutation } \\
\text { number of nonsense mutation } \\
\text { number of nonstop mutation } \\
\text { number of RNA mutation } \\
\text { number of silent mutation } \\
\text { number of splice site mutation }\end{array}$ & $\begin{array}{l}45.1 \pm 31.8 \\
28.1 \pm 20.1 \\
2.1 \pm 2.2 \\
0.1 \pm 0.2 \\
2.8 \pm 2.7 \\
11.1 \pm 8.7 \\
1.1 \pm 1.4 \\
\end{array}$ & \begin{tabular}{|l|}
$68.4 \pm 54.3$ \\
$43.3 \pm 35.3$ \\
$3.4 \pm 4.0$ \\
$0.1 \pm 0.3$ \\
$3.4 \pm 2.7$ \\
$16.9 \pm 15.1$ \\
$1.3 \pm 1.4$ \\
\end{tabular} & \begin{tabular}{|l}
$93.9 \pm 73.4$ \\
$61.6 \pm 48.2$ \\
$5.3 \pm 6.2$ \\
$0.2 \pm 0.4$ \\
$3.4 \pm 2.5$ \\
$21.9 \pm 17.4$ \\
$1.5 \pm 1.5$ \\
\end{tabular} & \begin{tabular}{|l}
$79.6 \pm 48.7$ \\
$52.8 \pm 2.9$ \\
$3.5 \pm 3.0$ \\
$0.1 \pm 0.2$ \\
$4.0 \pm 3.4$ \\
$17.7 \pm 1.6$ \\
$1.6 \pm 1.6$ \\
\end{tabular} & $<0.001$ \\
\hline Total number of mutations & $48.6 \pm 33.4$ & $72.7 \pm 54.7$ & $96.9 \pm 73.9$ & $85.9 \pm 51.3$ & $<0.001$ \\
\hline
\end{tabular}

was not associated with $\mathrm{ER}(\mathrm{rho}=0.029, P=0.864)$ or HLA-ABC (rho $=0.005, P=0.978$ ) expression. We also examined ER and HLA-ABC expression in normal breast tissue of 45 cancer patients, and also found a significantly negative correlation ( $\mathrm{rho}=-0.307, P=0.036$ ).

\section{Analysis of TCGA data}

To test our hypotheses that high number of mutations would produce more immunogenic mutations and that TILs would be more abundant in those tumors, we analyzed 396 TCGA breast cancer cases according to the PAM50 predictor. $C D 3 D, C D 3 E, C D 3 G, H L A-A$, and $H L A-C$ gene expression and the numbers of mutations were higher in HER2-enriched and basal-like subtypes than in luminal tumors (Table 5). $C D 8 B$ and $H L A-B$ expression were highest in basal-like tumors. ESR 1 gene expression showed a significant negative correlation with $H L A-A(\mathrm{rho}=-0.154, P=0.002)$ and $C D 8 B(\mathrm{rho}=-0.315$, $P<0.001$ ) gene expression (Figure 4).

When all tumors were analyzed, the $C D 8 B$ gene expression level was significantly correlated with the gene expression levels of $C D 3 D, C D 3 E, C D 3 G, H L A-A$, $H L A-B$, and $H L A-C$ (rho $=0.448-0.792, P<0.001$ ). However, $C D 8 B$ gene expression was not associated with the total number of mutations ( $r h o=0.029, P=0.566$ ). $H L A-A$ gene expression also showed no correlation with the total number of mutations ( $r h o=-0.026, P=0.603$ ). In subgroup analysis, positive correlation was seen between $C D 8 B$ and $H L A-A$ expression in all subtypes (rho $>0.290$, $P<0.046)$. However, the total number of mutations was not associated with $C D 8 B$ or $H L A-A$ gene expression in each subtype of tumors (Figure 5).

We also analyzed the expression of IFN signaling molecules to assess their expression level in each molecular subtype and their relationship with TILs and $H L A$ expression. Expression of the Type 1 and 2 IFN receptor genes (IFNAR1, IFNAR2, IFNGR1, and IFNGR2) and IFN inducible gene $M X 1$ were generally higher in HER2-enriced and basal-like subtypes than in luminal tumors (Table 5). Expression of IFN signaling molecules showed a significant positive correlation with $H L A \mathrm{~s}, C D 3$, and $C D 8$ gene expression (Figure 4). 
Analysis of CCLE data

To confirm the negative correlation between ESR1 and $H L A$ gene expression and the positive correlation between expression level of IFN signaling molecules and HLA genes, we analyzed CCLE data set. In 59 breast cancer cell lines, $H L A$ gene expression was inversely correlated with ESR1 expression and positively correlated with expression of IFN associated genes (Figure 6).
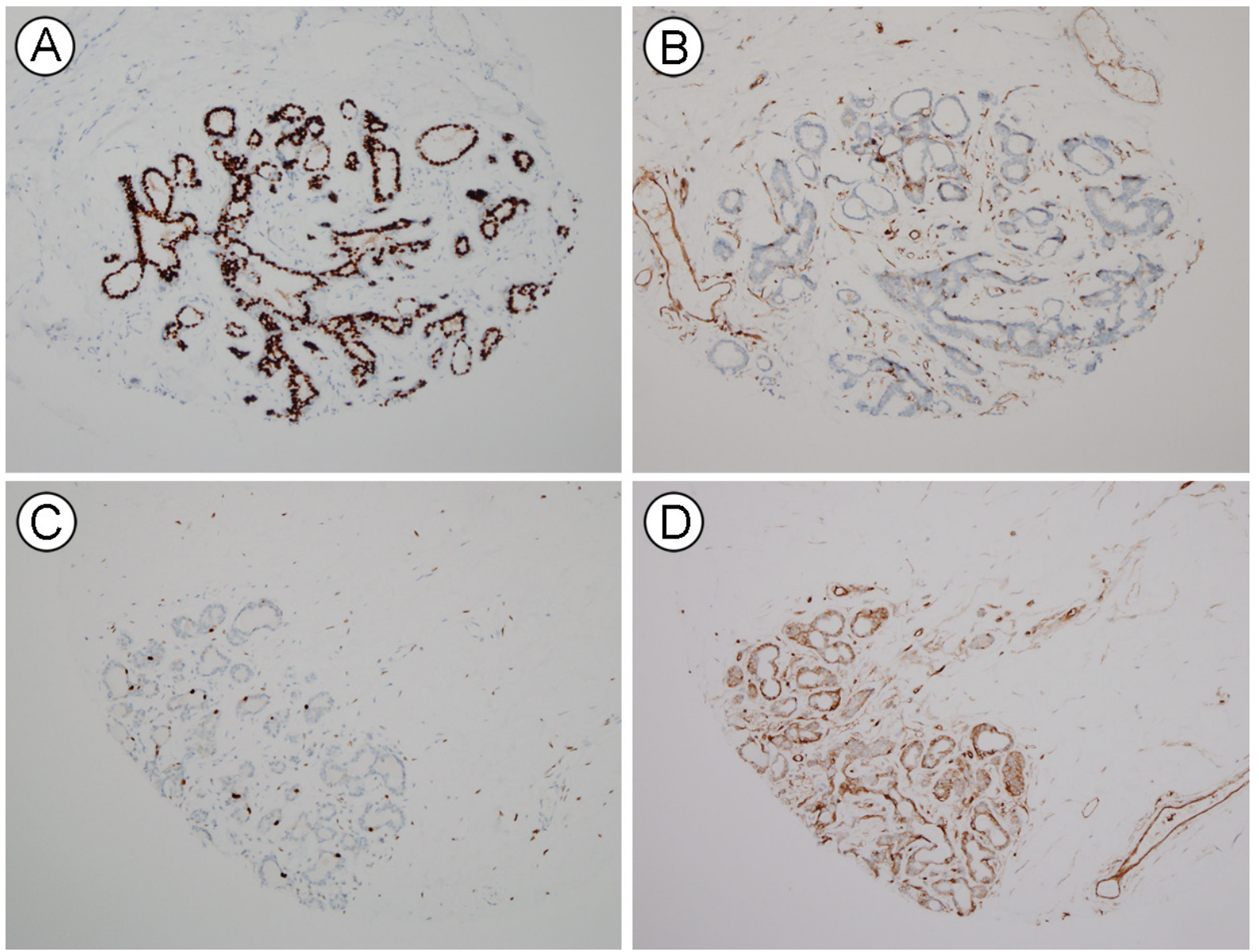

Figure 3: HLA-ABC and ER expression in normal breast luminal cells. A., B. A lobule with high ER (A) and low HLA-ABC (B) expression. C., D. Another lobule with low ER (C) and high HLA-ABC (D) expression.

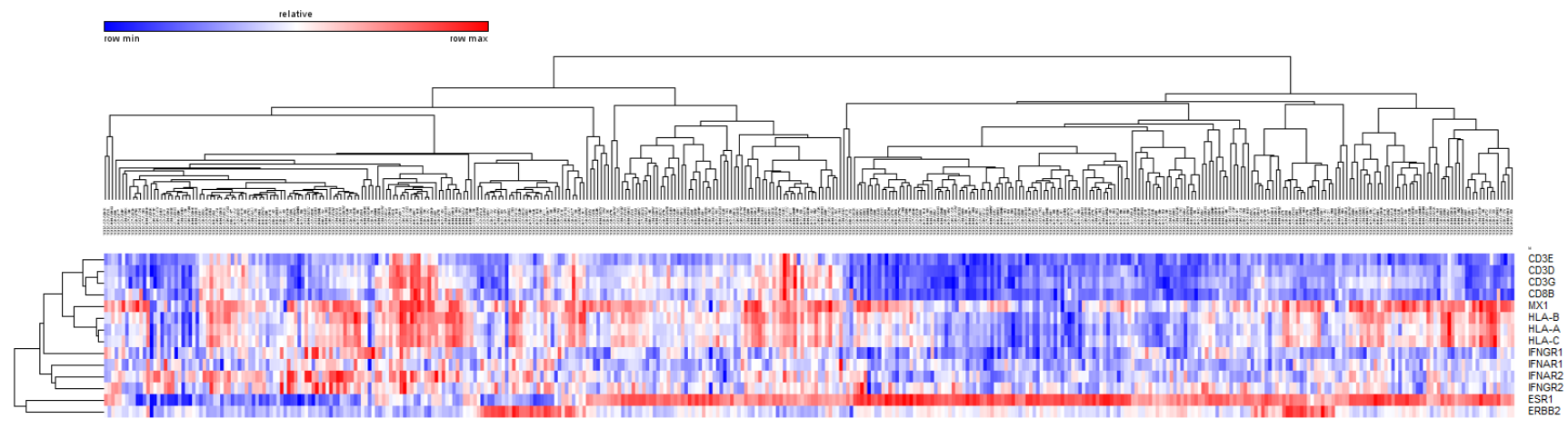

Figure 4: Unsupervised hierarchical clustering of breast cancers in the TCGA dataset using CD3, CD8, ESR1, HER2, $H L A$, and interferon signaling associated gene expression. 
A

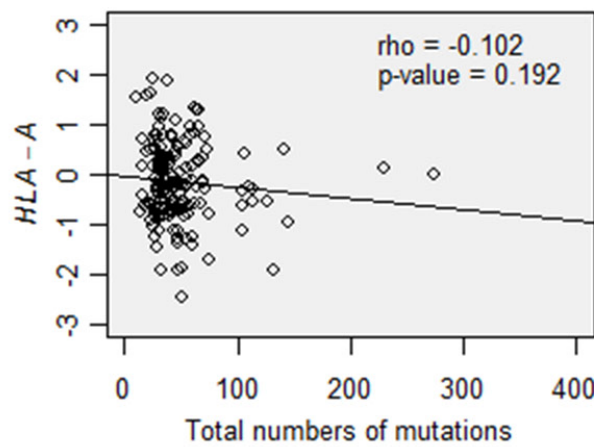

HER2-enriched

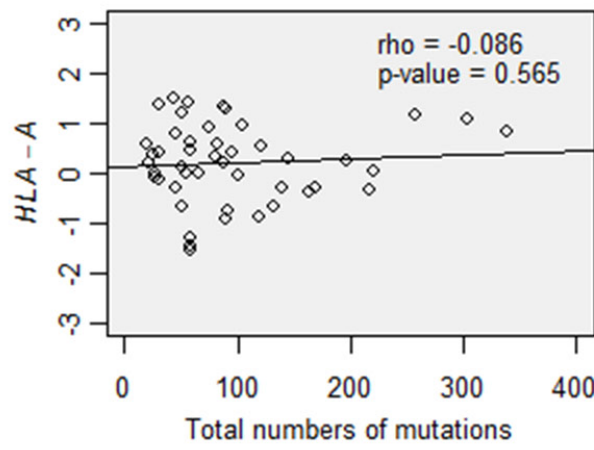

B

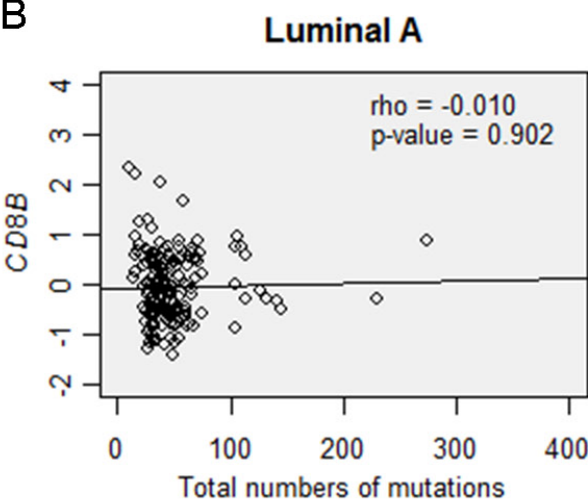

HER2-enriched

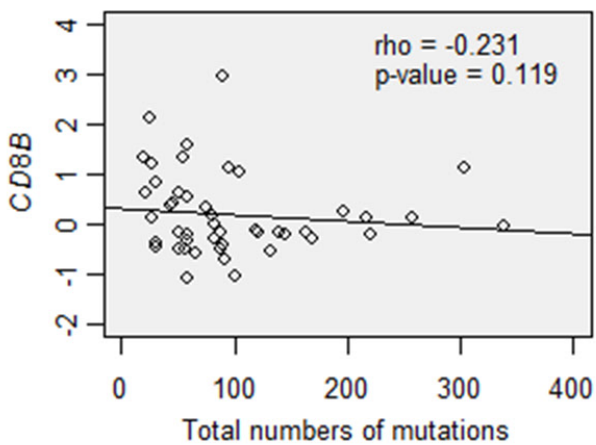

Luminal B

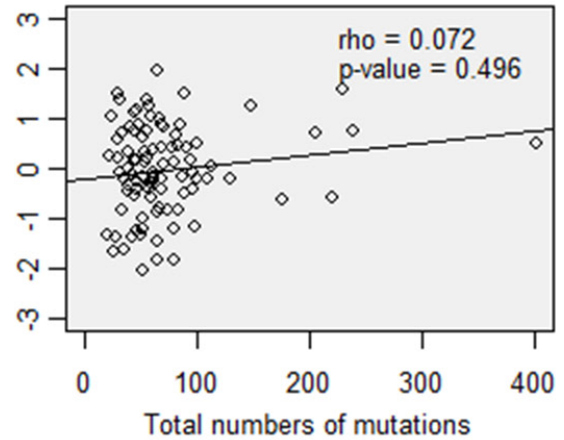

Basal-like

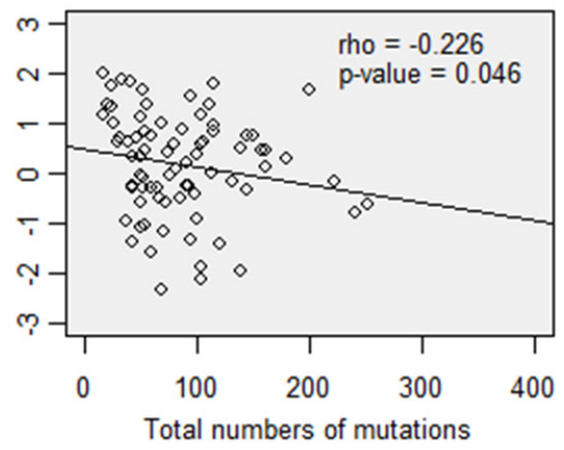

Luminal B

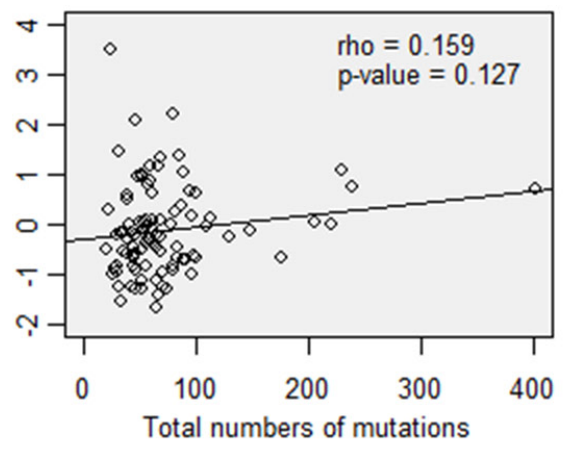

Basal-like

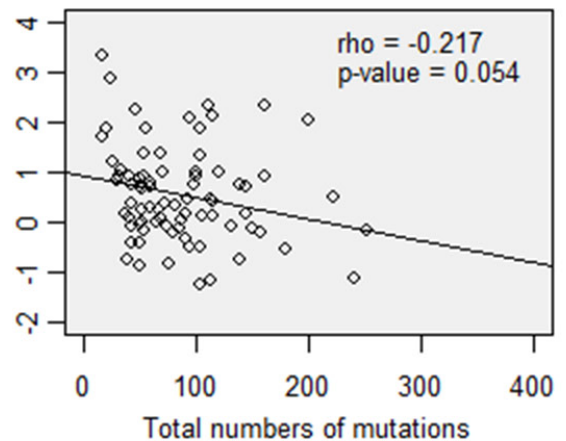

Figure 5: Correlations between the total number of mutations and A. $H L A-A$ gene expression and B. CD8B gene expression in the tumor subtypes of TCGA data. 


\section{DISCUSSION}

To the best of our knowledge, this study is the first to show different level of expression of HLA-ABC in each breast cancer subtype and its close relationship with TILs. We wanted to answer the questions why some breast cancers have abundant TILs and how HLA expression of tumor cells and TILs are involved. We could suggest two possible explanations for the close relationship between TILs and HLA expression. In first, the genomic instability of cancer may produce an immunogenic mutation that triggers an influx of lymphocytes to the cancer. The activated TILs could then produce IFN $\gamma$, which is a potent HLA inducer that stimulates $H L A$ gene transcription [10]. To test this hypothesis, we analyzed the number of mutations and the gene expression of breast cancer from the TCGA data. Even though we found more mutations and higher expression of $C D 3, C D 8$, and $H L A$ genes in HER2-enriched and basal-like tumors than in luminal tumors, there was no correlation between the total number of mutations and $H L A$ or $C D 8$ gene expression in any molecular subtype.

Alternatively, HLA expression may be increased due to some unknown mechanism and promote presentation of intracellular molecules on the surface of tumor cells. TILs may then be effectively introduced to the tumor microenvironment. We revealed that the expression of the Type 1 and 2 IFN receptor genes (IFNARI, IFNAR2, $I F N G R 1$, and IFNGR2) and IFN inducible gene $M X 1$ was generally higher in HER2-enriced and basal-like subtypes than in luminal tumors and showed a significant positive correlation with $H L A \mathrm{~s}, C D 3$, and $C D 8$ gene expression in TCGA data. Therefore, increased IFN signaling could be suggested as the cause of increased HLA expression and better antigen presentation on the surface of tumor cells. Interestingly, Sistigu et al. [13] recently found type I IFN autocrine and paracrine circuitries on tumor cells and their prognostic and predictive significance in breast cancer. We also confirmed positive correlation between expression of HLAs and IFN associated molecules in CCLE data. Since

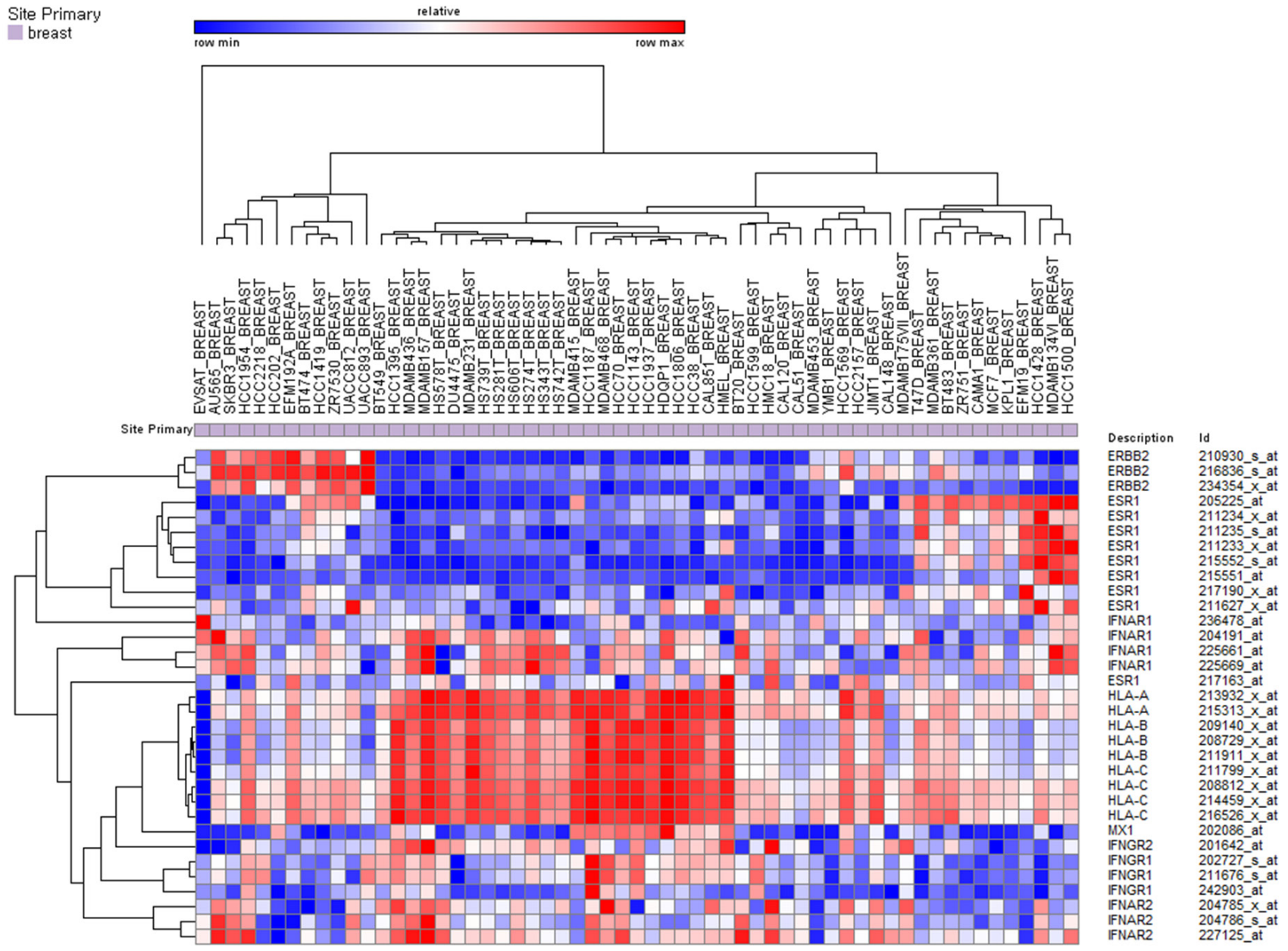

Figure 6: Unsupervised hierarchical clustering of breast cancer cell lines in the CCLE dataset using ESR1, HER2, $H L A$, and interferon signaling associated gene expression. 
breast cancer cell lines are only composed of epithelial cells, the effect of IFN $\gamma$ produced by lymphocytes for the induction of HLA gene expression can be excluded, which in turn, emphasizes the importance of autonomous IFN signaling in tumor cells. Mostafa et al. [15] reported that estradiol-ER $\alpha$ signaling plays a negative role in IFN $\gamma$ inducible MHC II expression via reducing expression of class II transactivator (CIITA), which increases expression of MHC I and II, in breast cancer cells. Further research to explore the mechanism of increased IFN signaling in breast cancer is needed to improve our understanding about TILs.

We found a negative correlation between ER and HLA-ABC protein expression in our consecutive breast cancer cohort, non-neoplastic breast tissues, and normal luminal cells of cancer patients. Santagata et al. [16] meticulously examined the expression of various markers, including ER, CK5/14/17, and Ki67, and found four mutually exclusive subsets of luminal cells in reduction mammoplasty tissue: $\mathrm{ER}^{+}, \mathrm{CK} 5 / 14 / 17^{+}$, ER CK5/14/17' and $\mathrm{Ki}^{+} 7^{+}$cells. In that study, each lobule showed different enrichments of $\mathrm{ER}^{+}, \mathrm{CK} 5 / 14 / 17^{+}$, and $\mathrm{Ki}^{+} 7^{+}$cells. We also found various ER expression patterns in each normal tissue sample. For example, we found a lobule with high ER and low HLA-ABC expression and another lobule with low ER and high HLA-ABC expression. We also confirmed a negative correlation between ESR1 and HLA gene expression in TCGA and CCLE data.

From our present findings, we speculate that a low number of TILs in $\mathrm{HR}^{+}$tumors may be associated with a higher expression of ER and a lower expression of HLA. Therefore, immune checkpoint inhibitors, which are increasingly being used and require pre-existing $\mathrm{CD}^{+} \mathrm{T}$ cells as a biologic target, may not be so effective in $\mathrm{HR}^{+}$ breast cancer [17]. To promote a higher immune response, strategies that can increase expression of the HLA protein may be helpful. Recently, some studies have reported the ability of low-dose chemotherapy and radiation to modify the tumor microenvironment $[18,19]$. Chemotherapy can induce inflammatory cytokines that increase $\mathrm{T}$ cell influx whereas radiation can also enhance Fas expression and Fas-dependent cytotoxic lymphocyte killing of tumor cells and increase MHC I molecules. In addition, further studies exploring the relationship between ER and HLA expression in breast tissue and the mechanism of TIL enrichment in TNBC are warranted to discover effective ways to improve patients' immune responses to cancer.

In summary, HLA expression is inversely correlated with ER expression in normal luminal cells and breast cancer and positively correlated with TILs and expression of IFN-associated molecules in breast cancer. Further investigation of the mechanism of how higher HLA expression and TIL influx are related in TNBC may help us find new therapeutic strategies to boost the host immune response.

\section{MATERIALS AND METHODS}

\section{Patients and tissue specimens}

Two sets of breast cancer and one set of nonneoplastic breast tissue samples were used. The first series included 688 consecutive breast cancer patients who underwent surgery for primary breast cancer between 1993 and 1998 at Asan Medical Center, Seoul, Korea, and who had formalin-fixed, paraffin-embedded, tissue samples for analysis. A total of 769 TNBC patients between 2004 and 2010 at Asan Medical Center were included as the second series (Supplementary Data). All patients were preoperatively chemo- and radiotherapy naïve.

For non-neoplastic breast samples, 15 cases of mammary hamartoma and 26 cases of reduction mammoplasty were included. No patients had a history of breast cancer. Clinicopathologic information was obtained from the patients' medical records and surgical pathologic reports. Exemption from informed consent after de-identification of information was approved by the Institutional Review Board of Asan Medical Center. This study has well followed the REMARK guidelines [20].

\section{Histological evaluation}

The hematoxylin and eosin (H\&E)-stained slides were reviewed by two pathologists (H.J.L. and G.G.). Slides were histopathologically analyzed for TILs (defined as the percentage of stroma of invasive carcinoma infiltrated by lymphocytes in 10\% increments; if less than $10 \%$ of stroma was infiltrated by TILs, $1 \%$ or $5 \%$ criteria were used; all available full-sections were evaluated), histologic subtype and grade, tumor size, pT stage, pN stage, and lymphovascular invasion [1, 21]. The histologic type was defined based on the 2012 WHO classification criteria, and the histologic grade was assessed using the modified Bloom-Richardson classification [22].

\section{Cell lines}

Human breast cancer cell lines MDA-MB-231, MDA-MB-468, MDA-MB-436, T47D, BT474, BT20, ZR-75-1, MCF-7, and SK-BR-3 from American type culture collection were used as controls for HLA-ABC immunohistochemistry. Cells were grown in RPMI-1640 media with $10 \%$ fetal bovine serum and $1 \%$ penicillinstreptomycin. Cell lines have been tested and authenticated and verified as mycoplasma free. Formalin-fixed, paraffinembedded cell blocks were generated. 


\section{Tissue microarray construction and immunohistochemical evaluation}

Formalin-fixed, paraffin-embedded, tissue samples were arrayed with a tissue-arraying instrument as previously described [23]. Each sample was arrayed in three $1-\mathrm{mm}$ diameter cores to minimize tissue loss and overcome tumor heterogeneity. Tissue microarray sections were stained with an automatic immunohistochemical staining device (Benchmark XT; Ventana Medical Systems, Tucson, AZ). Antibodies used in this study are summarized in Supplementary Table S3. As controls for HLA-ABC, cell blocks from human breast cancer cell lines were used (Supplementary Data and Supplementary Figure $\mathrm{S} 1$ ).

ER and PR levels were regarded as positive if there was at least $1 \%$ positive tumor nuclei staining [24]. In addition, the Allred score, which is the sum of intensity score (0-3) and proportion score (0-5), was calculated for ER and PR [25]. $\mathrm{HR}^{+}$tumors are defined as those with positive ER and/or PR. HER2-overexpressing tumors were defined as those with scores of $3+$ by immunohistochemistry or gene amplification by silver in situ hybridization (SISH) [26]. For CK5/6 and epidermal growth factor receptor (EGFR), any positive cytoplasmic and membranous staining was considered as positive [23]. The percentage of cytoplasmic CK5-positive cells was evaluated in normal tissue.

The HLA-ABC intensity was evaluated as a fourvalue intensity score $(0,1,2$, and 3$)$. The percentage of membranous and/or cytoplasmic expression of HLA$\mathrm{ABC}$ was also evaluated. An "immunoreactive score" was generated as the product of the intensity and the percentage of positive cells. We correlated immunoreactive score of HLA-ABC with ER Allred score. We also categorized HLA-ABC expression in tumor cells as one of three levels as previously described [strongly positive, expression in more than $75 \%$ of tumor cells; weakly positive, expression between $25 \%$ and $75 \%$ of tumor cells; negative, loss of expression in more than $75 \%$ of tumor cells] [12].

The immunostained tissue microarray slides for CD8 and CD69 were scanned using a digital microscopy scanner Pannoramic 250 FLASH (3DHISTECH Ltd., Budapest, Hungary). The numbers of $\mathrm{CD}^{+}$and $\mathrm{CD} 69^{+}$ cells in tissue microarray cores were counted by the NuclearQuant module of Pannoramic Viewer 1.15.2 (3DHISTECH Ltd).

\section{TCGA and CCLE data}

The TCGA data portal was used to download the breast cancer data [27]. A total of 396 cases of breast cancer were analyzed according to the PAM50 predictor. We downloaded level 3 gene expression data derived from an Agilent custom 244K whole genome microarray and somatic mutation data using exome sequencing from Illumina Genomic Analyzer. Gene expression level was median centered by genes.

Gene expression of 59 breast cancer cell lines using GeneChip Human Genome U133 Plus 2.0 Array included in CCLE was analyzed using GENE-E software, version 3.0.230 [28].

The five analysis sets are shown in Supplementary Table S4 where we have indicated the specific evaluations that were performed for each set of data.

\section{Statistical analysis}

All statistical analyses were performed using SPSS statistical software (version 18; SPSS, Chicago, IL). A Kruskal-Wallis test, chi-square test, linear-bylinear association test, Spearman's correlation, log-rank test, and Cox proportional hazards regression model were used as appropriate. All tests were two-sided and statistical significance was set at $5 \%$.

\section{ACKNOWLEDGMENTS}

The authors thank to Dr. Jorge S. Reis-Filho and Charlotte K. Y. Ng (Memorial Sloan Kettering Cancer Center) for the advice about analysis of TCGA mutation data.

\section{CONFLICTS OF INTEREST}

All authors declare no conflicts of interest.

\section{GRANT SUPPORT}

This study was supported by a grant (HI15C0708) of the Korean Health Technology R\&D Project, Ministry of Health \& Welfare, Republic of Korea.

\section{REFERENCES}

1. Loi S, Sirtaine N, Piette F, Salgado R, Viale G, Van Eenoo F, Rouas G, Francis P, Crown JP, Hitre E, de Azambuja E, Quinaux E, Di Leo A, Michiels S, Piccart MJ and Sotiriou C. Prognostic and predictive value of tumor-infiltrating lymphocytes in a phase III randomized adjuvant breast cancer trial in node-positive breast cancer comparing the addition of docetaxel to doxorubicin with doxorubicinbased chemotherapy: BIG 02-98. J Clin Oncol. 2013; 31:860-867.

2. Denkert C, Loibl S, Noske A, Roller M, Muller BM, Komor M, Budczies J, Darb-Esfahani S, Kronenwett R, Hanusch C, von Torne C, Weichert W, Engels K, Solbach C, Schrader I, Dietel M, et al. Tumor-associated lymphocytes as an independent predictor of response to neoadjuvant chemotherapy in breast cancer. J Clin Oncol. 2010; 28:105- 
113.

3. Lee HJ, Seo JY, Ahn JH, Ahn SH and Gong G. Tumorassociated lymphocytes predict response to neoadjuvant chemotherapy in breast cancer patients. J Breast Cancer. 2013; 16:32-39.

4. Seo AN, Lee HJ, Kim EJ, Kim HJ, Jang MH, Lee HE, Kim YJ, Kim JH and Park SY. Tumour-infiltrating CD8+ lymphocytes as an independent predictive factor for pathological complete response to primary systemic therapy in breast cancer. Br J Cancer. 2013; 109:2705-2713.

5. Mohammed ZM, Going JJ, Edwards J, Elsberger B and McMillan DC. The relationship between lymphocyte subsets and clinico-pathological determinants of survival in patients with primary operable invasive ductal breast cancer. Br J Cancer. 2013; 109:1676-1684.

6. Mohammed ZM, Going JJ, Edwards J, Elsberger B, Doughty JC and McMillan DC. The relationship between components of tumour inflammatory cell infiltrate and clinicopathological factors and survival in patients with primary operable invasive ductal breast cancer. Br J Cancer. 2012; 107:864-873.

7. Adams S, Gray RJ, Demaria S, Goldstein L, Perez EA, Shulman LN, Martino S, Wang M, Jones VE, Saphner TJ, Wolff AC, Wood WC, Davidson NE, Sledge GW, Sparano JA and Badve SS. Prognostic value of tumor-infiltrating lymphocytes in triple-negative breast cancers from two phase III randomized adjuvant breast cancer trials: ECOG 2197 and ECOG 1199. J Clin Oncol. 2014; 32:2959-2966.

8. Phan GQ and Rosenberg SA. Adoptive cell transfer for patients with metastatic melanoma: the potential and promise of cancer immunotherapy. Cancer Control. 2013; 20:289-297.

9. Brown SD, Warren RL, Gibb EA, Martin SD, Spinelli JJ, Nelson BH and Holt RA. Neo-antigens predicted by tumor genome meta-analysis correlate with increased patient survival. Genome Res. 2014; 24:743-750.

10. Agrawal S and Kishore MC. MHC class I gene expression and regulation. J Hematother Stem Cell Res. 2000; 9:795812.

11. Leone P, Shin EC, Perosa F, Vacca A, Dammacco F and Racanelli V. MHC class I antigen processing and presenting machinery: organization, function, and defects in tumor cells. J Natl Cancer Inst. 2013; 105:1172-1187.

12. Torigoe T, Asanuma H, Nakazawa E, Tamura Y, Hirohashi Y, Yamamoto E, Kanaseki T, Hasegawa T and Sato N. Establishment of a monoclonal anti-pan HLA class I antibody suitable for immunostaining of formalin-fixed tissue: unusually high frequency of down-regulation in breast cancer tissues. Pathol Int. 2012; 62:303-308.

13. Sistigu A, Yamazaki T, Vacchelli E, Chaba K, Enot DP, Adam J, Vitale I, Goubar A, Baracco EE, Remedios C, Fend L, Hannani D, Aymeric L, Ma Y, Niso-Santano M, Kepp O, et al. Cancer cell-autonomous contribution of type I interferon signaling to the efficacy of chemotherapy. Nat
Med. 2014; 20:1301-1309.

14. Lee HJ, Kim JY, Park IA, Song IH, Yu JH, Ahn JH and Gong G. Prognostic Significance of Tumor-Infiltrating Lymphocytes and the Tertiary Lymphoid Structures in HER2-Positive Breast Cancer Treated With Adjuvant Trastuzumab. Am J Clin Pathol. 2015; 144:278-288.

15. Mostafa AA, Codner D, Hirasawa K, Komatsu Y, Young $\mathrm{MN}$, Steimle V and Drover S. Activation of ERalpha signaling differentially modulates IFN-gamma induced HLA-class II expression in breast cancer cells. PLoS One. 2014; 9:e87377.

16. Santagata S, Thakkar A, Ergonul A, Wang B, Woo T, Hu R, Harrell JC, McNamara G, Schwede M, Culhane AC, Kindelberger D, Rodig S, Richardson A, Schnitt SJ, Tamimi RM and Ince TA. Taxonomy of breast cancer based on normal cell phenotype predicts outcome. J Clin Invest. 2014; 124:859-870.

17. Tumeh PC, Harview CL, Yearley JH, Shintaku IP, Taylor EJ, Robert L, Chmielowski B, Spasic M, Henry G, Ciobanu V, West AN, Carmona M, Kivork C, Seja E, Cherry G, Gutierrez AJ, et al. PD-1 blockade induces responses by inhibiting adaptive immune resistance. Nature. 2014; 515:568-571.

18. Kwilas AR, Donahue RN, Bernstein MB and Hodge JW. In the field: exploiting the untapped potential of immunogenic modulation by radiation in combination with immunotherapy for the treatment of cancer. Front Oncol. 2012; 2:104.

19. Kershaw MH, Devaud C, John LB, Westwood JA and Darcy PK. Enhancing immunotherapy using chemotherapy and radiation to modify the tumor microenvironment. Oncoimmunology. 2013; 2:e25962.

20. McShane LM, Altman DG, Sauerbrei W, Taube SE, Gion M, Clark GM and Statistics Subcommittee of the NCIEWGoCD. Reporting recommendations for tumor marker prognostic studies. J Clin Oncol. 2005; 23:90679072.

21. Salgado R, Denkert C, Demaria S, Sirtaine N, Klauschen F, Pruneri G, Wienert S, Van den Eynden G, Baehner FL, Penault-Llorca F, Perez EA, Thompson EA, Symmans WF, Richardson AL, Brock J, Criscitiello C, et al. The evaluation of tumor-infiltrating lymphocytes (TILs) in breast cancer: recommendations by an International TILs Working Group 2014. Ann Oncol. 2015; 26:259-271.

22. Lakhani SR EI, Schnitt SJ, Tan PH, van de Vijver MJ, editor. (2012). WHO Classification of Tumours of the Breast. (Lyon: International Agency for Research on Cancer).

23. Lee HJ, Seo AN, Park SY, Kim JY, Park JY, Yu JH, Ahn JH and Gong G. Low prognostic implication of fibroblast growth factor family activation in triple-negative breast cancer subsets. Ann Surg Oncol. 2014; 21:1561-1568.

24. Hammond ME, Hayes DF, Wolff AC, Mangu PB and Temin S. American society of clinical oncology/college 
of american pathologists guideline recommendations for immunohistochemical testing of estrogen and progesterone receptors in breast cancer. J Oncol Pract. 2010; 6:195-197.

25. Harvey JM, Clark GM, Osborne CK and Allred DC. Estrogen receptor status by immunohistochemistry is superior to the ligand-binding assay for predicting response to adjuvant endocrine therapy in breast cancer. J Clin Oncol. 1999; 17:1474-1481.

26. Wolff AC, Hammond ME, Hicks DG, Dowsett M, McShane LM, Allison KH, Allred DC, Bartlett JM, Bilous M, Fitzgibbons P, Hanna W, Jenkins RB, Mangu PB, Paik S, Perez EA, Press MF, et al. Recommendations for human epidermal growth factor receptor 2 testing in breast cancer: American Society of Clinical Oncology/College of
American Pathologists clinical practice guideline update. Arch Pathol Lab Med. 2014; 138:241-256.

27. Network CGA. Comprehensive molecular portraits of human breast tumours. Nature. 2012; 490:61-70.

28. Reich M, Liefeld T, Gould J, Lerner J, Tamayo P and Mesirov JP. GenePattern 2.0. Nat Genet. 2006; 38:500-501. 